\title{
Intraspecific morphometric variability in the populations of Barilius bendelisis (Hamilton) from the Alaknanda basin of Central Himalaya
}

\section{Sumit Kumar}

Department of Zoology and Biotechnology, H.N.B. Garhwal University, Srinagar-Garhwal246174 (Uttarakhand), India

Deepak Singh*

Department of Zoology and Biotechnology, H.N.B. Garhwal University, Srinagar-Garhwal246174 (Uttarakhand), India

*Corresponding author. E-mail: bhandaridrdeepak5@gmail.com
Article Info

DOI: 10.31018/jans.v10i4.1920

Received: October 11, 2018

Revised: November 5, 2018

Accepted: November 16, 2018

\section{How to Cite}

Kumar, S. and Singh, D. (2018). Intraspecific morphometric variability in the populations of Barilius bendelisis (Hamilton) from the Alaknanda basin of Central Himalaya. Journal of Applied and Natural Science, 10(4): 1199-1203 nant function analysis (DFA) were used to differentiate the populations of $B$, bende extracted eight significant morphometric traits explaining $87.9 \%$ of total variation among the three populations. DFA revealed that $83.1 \%$ specimens were retained into their original groups. Environmental factors were attributed to phenotypic variations among closely related populations. The present study is a first attempt on stock structure of $B$. bendelisis from different tributaries of Alaknanda river. The study will help in future conservation and management of this fish species across Uttarakhand region, India.

Keywords: Barilius bendelisis, Hill trout, Intraspecific, Variability.

\section{INTRODUCTION}

The study of morphological characters in Ichthyology is of great importance for characterizing fish stocks (Cadrin, 2000). Local fish population (stock) adapts to particular environment and has genetic difference from other stocks (MacLean and Evans, 1981). According to Costa et al. (2003), phenotypic characters are more affected by the environmental influence rather than genetic characters. Biologists took interest in understanding the mechanism of phenotypic variations since the advent of Darwin's theory of evolution (Pfennig et al., 2010).

In order to overcome the weaknesses of conventional morphometric analysis, the truss network system (Strauss and Bookstein, 1982) has been used at present for the purposes of stock identification, which essentially discriminates 'phenotypic stocks', that are groups of individuals having similar phenotypic traits (Booke, 1981). Barilius bendelisis (Hamilton, 1807) has recently got attention as one of the important species for aquaculture (Suresh and Mandal, 2001). It comes under the family Cyprinidae and well distributed in the lotic water bodies of Himalayan region. So far fewer studies have been done on the morphometric and meristic counts of hill trout (Hazarika et al., 2011). Truss analysis revealed highly significant difference among 31 morphometeric parameters in the populations of snowtrout, Schizopyge niger (Heckel 1838) from Kashmir Himalaya (Mir et al., 2013a). Mir et al. (2015) also used truss morphometry to study intraspecific variation in $B$. bendelisis from four rivers of Central Indian Himalaya. Miyan et al. (2015) observed significant differences in twenty four morphometric measurements by truss morphometry in Clarias batrachus, from Ganga river basin. Kaoueche et al. (2016) also found morphometric variations among the populations of white seabream Diplodus sargus (Linneus, 1758) populations along the Tunisian coast using 25 truss measurements and 6 traditional measurements. Truss based morphometrics was also effectively used to observe variations in populations of Danio dangila (Hamilton, 1822) from different areas of North-East India by Banerjee et al. (2017).

Therefore, the present study was aimed at to examine the morphometric variations in populations of $B$. bendelisis from different tributaries of Alaknanda river using truss network analysis. The 
study will be instrumental for effective conservation and management of the fish stocks in future.

\section{MATERIALS AND METHODS}

Sampling: The specimens of $B$. bendelisis were collected from the three different tributaries, Dugadda Gad, Khankhra Gad and Khandah Gad, of Alaknanda before the breeding season and after the spawning season, with the help of local fishermen by using gill net, cast net and traditional Thali method from March 2015 to April 2016. A total 124 fish samples were collected from different spring-fed tributaries, Dugadda Gad (42 specimens), Khankhra Gad (40 specimens) and Khandah Gad (42 specimens). 10\% formalin was utilized to preserve the collected samples that were morphometrically analysed. The captured specimens were identified with the help of taxonomic keys of Day (1878), Talwar and Jhingran (1991), Mirza (1991) and Kullander et al. (1999).

Digitalization of specimens: After cleaning in running water the fish specimens were placed on a flat platform with graph paper as a back-ground. Fins were erected to make the origin and insertion points visible. Photographs were taken by means of a digital camera (Nikon D3400) from same angle and distance. Specific code was given to each specimen for proper identification.

Measurement of truss distances: The truss protocol used in the present study was based on fourteen landmarks (Mir et al., 2013b) and these landmarks were interconnected to get a network of 90 truss measurements (Fig. 2). A set of three softwares, tpsUtil, tpsDig2 v2.1 (Rohlf, 2006) and PAST (Paleontological Statistics; Hammer et al., 2001) was used to measure the truss distances of the digital images.

Statistical procedure: An allometric method suggested by Elliott et al. (1995) was used to correct the size dependent variation as " $M_{a d j}=M(L s / L 0)$ " where $M$ and $M_{a d j}$ represented original and the size adjusted measurements, respectively, LO and Ls were used for the standard length and overall mean standard length of fish. $b$ was slope of the regression of log $M$ on log LO for each character. The extracted ninety morphometric characters were subjected to a univariate analysis of variance to compare the populations of the different sampled sites of $B$. bendelisis. ANOVA extracted the significant variables $(p<0.05)$ which were later subjected to factor analysis. A maximum likelihood method of factor extraction was used. The significant measurements were also subjected to the discriminant function analysis (DFA) to calculate percentage of correctly classified fishes into their original groups. SPSS vers.20 and Microsoft Excel 2007 were used for statistical analysis of morphometric data.

\section{RESULTS}

Ninety variables were obtained by inter-

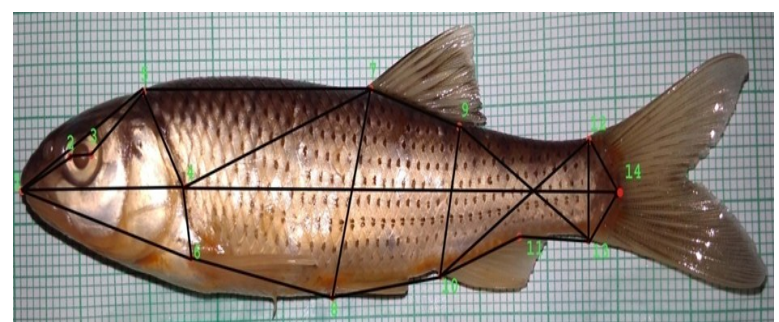

Fig. 1. Truss network of Barilius bendelisis showing the 14 landmarks: 1 tip of snout; 2 anterior border of eye; 3 posterior border of eye; 4 posterior border of operculum; 5 forehead (end of frontal bone); 6 pectoral fin origin; 7 dorsal fin origin; 8 pelvic fin origin; 9 dorsal fin termination; 10 origin of anal fin; 11 termination of anal fin; 12 dorsal side of caudal peduncle, 13 ventral side of caudal peduncle; 14 termination of lateral line.

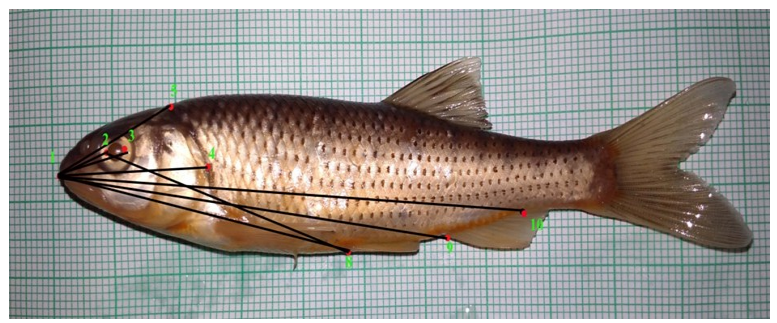

Fig. 2. Eight morphometric measurements showing significant loadings on three principal components.

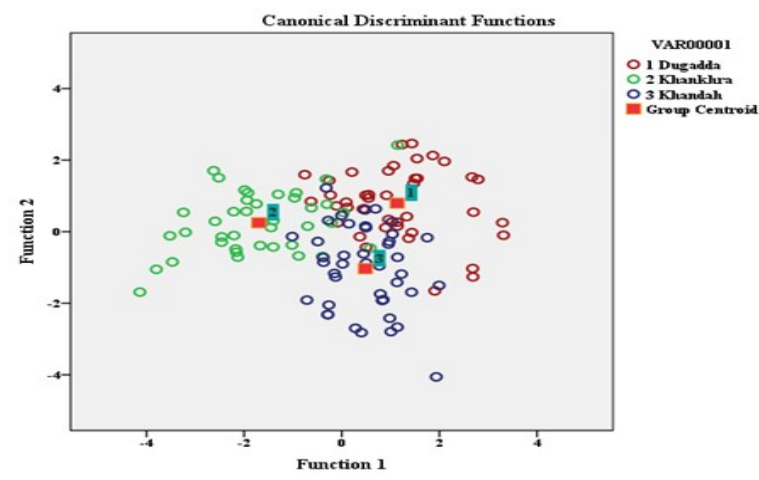

Fig. 3. Discriminant analysis plot representing distance among stocks of of Barilius bendelisis from three tributaries of Alaknanda river.

connecting the 14 landmarks in truss network system (Fig. 1). 8 significant $(p<0.05)$ characters were extracted by ANOVA from 90 morphometeric measurements. Principal component analysis extracted 3 factors having Eigen-values 3.8, 2.1 and 1.0 respectively from 8 truss measurements, explaining $83.1 \%$ of the total variance (Table 1). The truss distances with meaningful loadings on factor 1 were 1-2, 1-3, 1-4, 1-5 (Table 2), which explained $47.5 \%$ of the total variance. The second factor explained $27.0 \%$ of total variation from three variables, 1-8, 1-9, 2-8 which showed significant loadings on it. Remaining factor 3 explained $13.4 \%$ of the total variance and only one variable 1-10 had significant loading on it (Fig. 2). DFA classified $83.1 \%$ of specimens into their original 
Kumar, S. and Singh, D. / J. Appl. \& Nat. Sci. 10 (4): 1199-1203 (2018)

Table1. Three principal components explaining percentage of variance among morphometric measurements of Barilius bendelisis.

\begin{tabular}{lcccccc}
\hline Component & \multicolumn{3}{c}{ Initial Eigen values } & \multicolumn{3}{c}{ Extraction sums of Squared loadings } \\
\cline { 2 - 7 } & Total & \% of variance & $\begin{array}{c}\text { Cumulative } \\
\%\end{array}$ & Total & \% of variance & $\begin{array}{c}\text { Cumulative } \\
\%\end{array}$ \\
\hline PCA1 & 3.801 & 47.507 & 47.507 & 3.801 & 47.507 & 47.507 \\
PCA2 & 2.160 & 27.004 & 74.511 & 2.160 & 27.004 & 74.511 \\
PCA3 & 1.079 & 13.485 & 87.996 & 1.079 & 13.485 & 87.996 \\
\hline
\end{tabular}

Table 2. Loadings of three principal components (Significant loadings are highlighted).

\begin{tabular}{lccc}
\hline \multicolumn{4}{c}{ Component Matrix } \\
\cline { 2 - 4 } & PC1 & PC2 & PC3 \\
\hline VAR 1-2 & $\mathbf{0 . 9 5 5}$ & 0.088 & 0.056 \\
VAR 1-3 & $\mathbf{0 . 9 5 7}$ & 0.106 & 0.124 \\
VAR 1-4 & $\mathbf{0 . 8 5 0}$ & 0.176 & 0.205 \\
VAR 1-5 & $\mathbf{0 . 9 0 0}$ & 0.222 & 0.102 \\
VAR 1-8 & -0.164 & $\mathbf{0 . 9 3 5}$ & 0.218 \\
VAR 1-9 & 0.027 & $\mathbf{0 . 7 1 9}$ & -0.480 \\
VAR 1-10 & -0.390 & -0.038 & $\mathbf{0 . 8 4 6}$ \\
VAR 2-8 & -0.509 & $\mathbf{0 . 8 1 8}$ & 0.117 \\
\hline
\end{tabular}

groups. Wilks' Lambda test also showed highly significant variation in morphometric characters of $B$. bendelisis among three populations of Alaknanda river basin (Table 3 ). The percentage of correctly classified specimens was highest in Khankhra $(85.0 \%)$ followed by Dugadda $(83.3 \%)$ and Khandah (81.0\%). These morphometric variables were lying between the snout and anterior end of anal fin. The discriminant function plot obtained by DFA showed the phenotypic heterogeneity among three populations of $B$. bendelisis from Alaknanda River. Small intermingling among the three populations was also found (Fig. 3).

\section{DISCUSSION}

Fishes generally show higher degrees of variation within and between populations as compared to other organisms and are also more prone to environmentally-induced morphological variations (Wimberger, 1992). Turan et al. (2004) reported that isola-tion may result into phenotypic and genetic differentia-tion among fish populations

Table 3. Classification matrix of DFA and Wilks' Lambda based on truss morphometry $(83.1 \%$ of original grouped cases correctly classified).

\begin{tabular}{|c|c|c|c|c|}
\hline \multicolumn{5}{|c|}{ Predicted group membership } \\
\hline \multirow[t]{2}{*}{ Sampling Sites } & \multicolumn{3}{|c|}{ Alaknanda River } & \multirow[t]{2}{*}{ Total } \\
\hline & Dugadda & Khankhra & Khandah & \\
\hline Dugadda & 35 & 3 & 4 & 42 \\
\hline Khankhra & 3 & 34 & 3 & 40 \\
\hline Khandah & 5 & 3 & 34 & 42 \\
\hline \multicolumn{5}{|c|}{ Cross validated results (\%) } \\
\hline Dugadda & 83.33 & 7.14 & 9.52 & 100.0 \\
\hline Khankhra & 7.50 & 85.00 & 7.50 & 100.0 \\
\hline Khandah & 11.90 & 7.14 & 80.95 & 100.0 \\
\hline \multicolumn{5}{|l|}{ Wilks' Lambda } \\
\hline Test of Function(s) & Wilks' Lambda & Chi-square & $\mathrm{df}$ & Significance level \\
\hline 1 through 2 & 0.250 & 165.650 & 8 & 0.000 \\
\hline 2 & 0.620 & 57.057 & 3 & 0.000 \\
\hline
\end{tabular}

within a species. The results obtained from the present study indicated phenotypic plasticity among three populations of $B$. bendelisis from different streams of central Himalaya.

Discriminant function analysis (DFA) has been a useful tool to distinguish different stocks of the same species (Karakousis et al., 1991). In the present investigation, $83.1 \%$ of specimens were rightly classified into their respective groups by DFA. Wilks' Lambda test of DFA also proved significant morphometeric differences or heterogeneity among three populations of $B$. bendelisis. Turan et al. (2004) found significant morphometric heterogeneity among different populations of anchovy (Engraulis encrasicolus) from different areas of the Mediterranean Sea from DFA. Hossain et al. (2010) applied DFA and PCA to three populations of $L$. calbasu from three water bodies and reported environmental factors such as temperature, food availability, and local migration to be the causes of morphological variations among them. Similar findings were reported by Khan et al. (2012) in the populations of Channa punctatus from three Indian rivers.

The morphometeric variations among three populations of $B$. bendelisis from Alaknanda river could be due to variations in hydrological conditions and consequent phenotypic plasticity. The differences in current pattern, temperatures, turbidity, and land-use patterns among these drainages may result in to these variations. Some similar habitat attributes and their impacts may be associated with the closeness between stocks. Quilang et al. (2007) reported similar findings in silver perch Leiopotherapon plumbeus from three lakes in the 
Philippines. Poulet et al. (2004) also noted that the morphological characters of the fish are determined by environment and genetics, and the interaction between them.

Akbarzadeh et al. (2009) used 32 truss morphometric measurements to determine the variation among different stocks of pikefish (Sander lucioperca) from the southern Caspian Sea and found 20 significant morphometeric measurements. While in the present study only 8 significant morphometric measurements out of 90 reflected the phenotypic variations in the populations of $B$. bendelisis from the Alaknanda river indicating comparatively less variability in stocks. The truss system has been effective for stock separation within a species. In the present study, the truss protocol also revealed separation of $B$. bendelisis wild stocks in the three tributaries of Alaknanda river which may be associated with variations in some hydrological conditions. However, it is suggested that the present observations can further be confirmed from molecular and biochemical methods. Molecular genetic markers such as microsatellite and mtDNA applications along with morphometric studies may also be effective methods.

\section{Conclusion}

The present study provided information about morphological variability among different populations of $B$. bendelisis from three different springfed tributaries of Alaknanda river of central Himalaya. Truss based morphometrics was found effective to differentiate the stocks. Variation in some of the hydrological conditions in tributaries was attributed to the differences in the stocks. There is a need to frame separate management strategies in order to sustain the stocks for future use.

\section{ACKNOWLEDGEMENTS}

Authors are thankful to the Department of Zoology and Biotechnology, H.N.B. Garhwal University, Srinagar (Garhwal) for providing necessary facilities for conducting the present work. Local fishermen are also thankfully acknowledged to make the fish stock available for the study.

\section{REFERENCES}

1. Akbarzadeh, A., Farahmand, H., Shabani, A.A., Karami, M., Kaboli, M., Abbasi, K. and Rafiee, G.R. (2009). Morphological variation of the pikeperch Sander lucioperca (L.) in the southern Caspian Sea, using a truss system, J. Appl. Ichthyol, 25: 576-582.

2. Banerjee, T., Mahapatra, B.K and Patra, B.C. (2017). Morphomeristic characteristics of moustached Danio, Danio dangila (Hamilton, 1822) from North-East hilly region of India. Int. J. Fish. Aquat. Stud., 5(2): 389-393.

3. Booke, H.E. (1981). The conundrum of the stock concept: are nature and nurture definable in fishery science? Can. J. Fish. Aquat. Sci, 38: 1479-1480.

4. Cadrin, S.X. (2000). Advances in morphometric identification of fishery stocks. Rev. Fish Biol. Fish. 10: 91 $-112$.

5. Costa, J.L., De Almeida, P.R. and Costa, M.J. (2003). A morphometric and meristic investigation of Lusitanian toadfish Halobatrachus diductilus (Bloch and Schneider, 1801): evidence of population fragmentation on Portuguese coast. Sci. Mar., 67: 219-231.

6. Day, F. (1878). Fishes of India. Vol.1 and Vol 2. William Dawson and Sons Ltd., London.

7. Elliott, N.G., Haskard, K. and Koslow, J.A. (1995). Morphometric analysis of orange roughy (Hoplostethus atlanticus) off the continental slope of Southern Australia. J. Fish Biol., 46: 202-220.

8. Hammer, O., Harper, D.A.T. and Ryan, P.D. (2001). PAST: Palaeontological statistics software package for education and data analysis. Palaeontol. Electron.,4: 9.

9. Hazarika, A., Borah, U. and Bordoloi, L. (2011) Studies on morphometric measurements and meristic counts of hill trout (Barilius bendelisis, Hamilton) from the River Buroi at the boundary areas of Assam and Arunachal Pradesh, India. Indian J. Fund. Appl. Life Sci., 1: 194-198.

10.Hossain, M.A.R., Nahiduzzaman, M., Habiba, K.D.S., Mst, U. and Alam, M.S. (2010). Landmark-based morphometric and meristic variations of the endangered Carp, Kalibaus Labeo calbasu, from stocks of two isolated rivers, the Jamuna and Halda, and a hatchery. Zool. Stud., 49: 556-563.

11. Kaoueche, M., Bahri-Sfar, L., Hammami, I. and Hassine, O.K.B. (2016). Morphometric variations in white seabream Diplodus sargus (Linneus, 1758) populations along the Tunisian coast. Oceanologia, 87: $1-10$.

12.Karakousis, Y., Triantaphyllidis, C. and Economidis, P.S. (1991). Morphological variability among seven populations of brown trout, Salmon trutta L., in Greece. J. Fish Biol., 38: 807-817.

13.Khan, M.A., Miyan, K. and Khan, S. (2012). Morphometric variation of snakehead fish, Channa punctatus, populations from three rivers. J. Appl. Ichthyol., 28: 154-155.

14.Kullander, S.O., Fang, F., Delling, B. and Ahlander, E. (1999). The fishes of Kashmir valley. In : Nyman L., (ed.) River Jhelum, Kashmir Valley,99-162. Swedmar, The international consultancy group of the $\mathrm{Na}$ tional Board of Fisheries, Goteborgs, Lanstryckeri AB., Swedmar.

15.MacLean, J.A. and Evans, D.O. (1981). The stock concept, discreteness of fish stocks, and fisheries management. Can. J. Fish. Aquat. Sci, 38: 18891898.

16. Mir, J.I., Mir, F.A., Chandra, S. and Patiyal, R.S. (2013a). Pattern of morphological variations in Alghad snowtrout, Schizopyge niger (Heckel 1838) from Kashmir Himalaya using truss network analysis. Ichthyol. Res.,60(3): 256-262.

17.Mir, F.A., Mir, J.I., and Chandra, S. (2013b). Phenotypic variation in the Snowtrout Schizothorax richardsonii (Gray, 1832) (Actinopterygii: Cypriniformes: Cyprinidae) from the Indian Himalayas. Contrib. Zool., 82(3), 115-122.

18.Mir, J.I., Saxena, N., Patiyal, R.S. and Sahoo, P.K. (2015). Phenotypic differentiation of Barilius bendelisis (Cypriniformes: Cyprinidae) in four rivers from 
Central Indian Himalaya. Int. J. Trop. Biol., 63(1): 165 $-173$.

19.Mirza, M.R. (1991). A contribution to the systematics of the Schizothoracine fishes (Pisces: Cyprinidae) with the description of three new tribes. Pakistan Journal of Zoology, 23: 339-341.

20.Miyan, K., Khan, M.A., Patel, D.K., Khan, S. and Ansari, N.G. (2015). Truss morphometry and otolith microchemistry reveal stock discrimination in Clarias batrachus (Linnaeus, 1758) inhabiting the Gangetic river system. Fish. Res., 173: 294-302.

21.Pfennig, D.W., Wund, M.A., Snell-Rood, E.C., Cruickshank, T., Schlichting, C.D and Moczek, A.P. (2010). Phenotypic plasticity's impacts on diversification and speciation. Trends Ecol. Evol., 25: 459467.

22.Poulet, N., Berrebi, P., Crivelli, A.J., Lek, S. and Argillier, C. (2004). Genetic and morphometric variations in the pikeperch (Sander lucioperca L.) of a fragmented delta. Arch. Hydrobiol., 159: 531-554.

23.Quilang, J.P., Basiao, Z.U., Pagulayan, R.C., Roderos, R.R. and Barrios, E.B.(2007). Meristic and morphometric variation in the silver perch, Leiopo- therapon plumbeus (Kner, 1864), from three lakes in the Philippines. J. Appl. Ichthyol, 23: 561-567.

24.Rohlf, F.J. (2006). tpsDig2, ver. 2.1. State University of New York, Stony Brook.

25.Strauss, R.E. and Bookstein, F.L. (1982). The truss: body from reconstructions in morphometrics. Syst. Zool., 31: 113-135

26.Suresh, V.R. and Mandal, V.K. (2001). Aquaculture development possibility on Hills through integrated watershed management. Fish.Chimes, 21(4): 33-36.

27.Talwar, P.K. and Jhingran, A.G. (1991). Inland Fishes of India and Adjacent Countries. Vol.1. Balkema AA, Rotterdam.

28.Turan, C., Erguden, D., Gurlek, M., Basusta, N. and Turan, F. (2004). Morphometric structuring of the anchovy (Engraulis encrasicolus L.) in the black, Aegean and Northeastern Mediterranean seas. Turk. J. Vet. Anim. Sci, 28: 865-871.

29.Wimberger, P.H. (1992). Plasticity of fish body shape, the effects of diet, development, family and age in two species of Geophagus (Pisces, Cichlidae). Biol. J . Limnol. Soc., 45:197-218. 